\title{
Species recognition through wing interference patterns (WIPs) in Achrysocharoides Girault (Hymenoptera, Eulophidae) including two new species
}

\author{
Ekaterina Shevtsova ${ }^{1, \dagger}$, Christer Hansson ${ }^{2, \ddagger}$ \\ I Department of Biology, Lund University, Sölvegatan 35, SE-22362 Lund, Sweden 2 Scientific Associate of \\ the Natural History Museum, Cromwell Road, South Kensington, London SW7 5BD, United Kingdom \\ † urn:lsid:zoobank.org:author:470FE964-AB06-4DDF-AFA7-7027AC5A8FBA \\ ‡urn:lsid:zoobank.org:author:EC91EABD-7115-4B05-BC80-9195C86FA55D \\ Corresponding author: Ekaterina Shevtsova (ekaterina.shevtsova@biol.lu.se)
}

Academic editor: N. Johnson | Received 28 September 2011 | Accepted 25 November 2011 | Published 12 December 2011

urn:lsid:zoobank.org:pub:5A2CD134-5DC2-424C-9330-45C277E8E8BF

Citation: Shevtsova E, Hansson C (2011) Species recognition through wing interference patterns (WIPs) in Achrysocharoides Girault (Hymenoptera, Eulophidae) including two new species. ZooKeys 154: 9-30. doi: 10.3897/ zookeys. 154.2158

\begin{abstract}
Wing interference patterns (WIPs) are shown to be an important tool for species recognition in the genus Achrysocharoides Girault (Hymenoptera: Eulophidae). This is demonstrated by combining information from two previously published papers, comprising two cases of cryptic species, and by new material including the description of two new species, $A$. maieri and A. serotinae from North America. The cryptic species were initially separated through their distinct male WIPs. Subsequent analyses of the external morphology uncovered additional morphological differences supporting the original findings through WIPs, and biological data further strengthened the identity of these species. The new species described here also differ in their WIPs but the WIPs are similar in both sexes. Thus they provide a strong link between male and female and demonstrate that WIPs can also be useful for species recognition when the sexes are otherwise difficult to associate. Both new species are from Connecticut, USA, and were reared from Phyllonorycter propinquinella (Braun) (Lepidoptera: Gracillariidae) on black cherry (Prunus serotina); $A$. maieri has also been reared from $P h$. $n r$ crataegella on pin cherry (P. pensylvanica). To facilitate the identification of the new species they are included in a previously published key to North American species of Achrysocharoides. As a supplement to colourful WIPs we also demonstrate that grey scale images of uncoated wings from scanning electron microscopy can be used for visualization of the thickness distribution pattern in wing membranes.
\end{abstract}

Copyright E. Shevtsova, C. Hansson. This is an open access article distributed under the terms of the Creative Commons Attribution License 3.0 (CC-BY), which permits unrestricted use, distribution, and reproduction in any medium, provided the original author and source are credited. 


\section{Keywords}

taxonomy, cryptic species, structural colours, sexual dimorphism, wing membrane thickness, Chalcidoidea, Entedoninae, leafminer parasitoids, Achrysocharoides acerianus, Achrysocharoides platanoidae, Achrysocharoides robiniae, Achrysocharoides robinicolus, Achrysocharoides butus, Achrysocharoides latreilleii, Achrysocharoides albiscapus, Achrysocharoides maieri, Achrysocharoides serotinae, Phyllonorycter propinquinella, Phyllonorycter nr crataegella, Prunus serotina, Prunus pensylvanica

\section{Introduction}

Species of Achrysocharoides Girault (Hymenoptera: Eulophidae) are small parasitic wasps with transparent non-pigmented wings (Figs 1-6, 9). The short postmarginal vein in the fore wing is characteristic for the genus and the shape of the fore wing can be used to distinguish males of some species, but otherwise wings have been disregarded as non-informative neutral entities in this genus (e.g. Askew and Ruse 1974; Kamijo 1991). Recently wings in this group were discovered to display patterns with stable structural colours (Fig. 7), comparable to other insect groups with colourful wings such as butterflies (Shevtsova et al. 2011). These wing interference patterns (WIPs) become visible when transparent insect wings are seen against a dark background, and are most distinctive in small species with exceptionally thin wing membranes.

WIPs as a morphological character are so new that very little is known about the significance of these patterns for their bearers or for entomologists studying them, although they have already proven useful for generic-level classification in Eulophidae (Hansson 2011). The application of WIPs as a species character was first used in a study including two cases of cryptic species in Achrysocharoides (Hansson and Shevtsova 2010), where the initial species separation was based solely on male WIPs. However, data showing the usefulness of WIPs were withheld pending the publication of Shevtsova et al. (2011) where a general background to these patterns was outlined. In order to expand the knowledge of WIP diversity and to prove the usefulness of these patterns for studies at the species level it is important to link the information from these two publications. To further enhance this knowledge we also describe two new Achrysocharoides species with distinct WIPs.

The two new species of Achrysocharoides described here are from North America and the genus was initially recorded from this region by Miller (1962), as the genus Enaysma Delucchi, including six new species from Canada which were placed in the same subgenus (Pentenaysma Graham). Yoshimoto (1977) synonymized Enaysma with Achrysocharoides, and added nine species (six newly described) to the six described by Miller. He also separated the 15 species into two newly created species groups, thus abandoning the division into subgenera. The latest comprehensive treatment of North American Achrysocharoides is by Kamijo (1991), who treated 18 species, including four new species and one new synonym, separated into five 


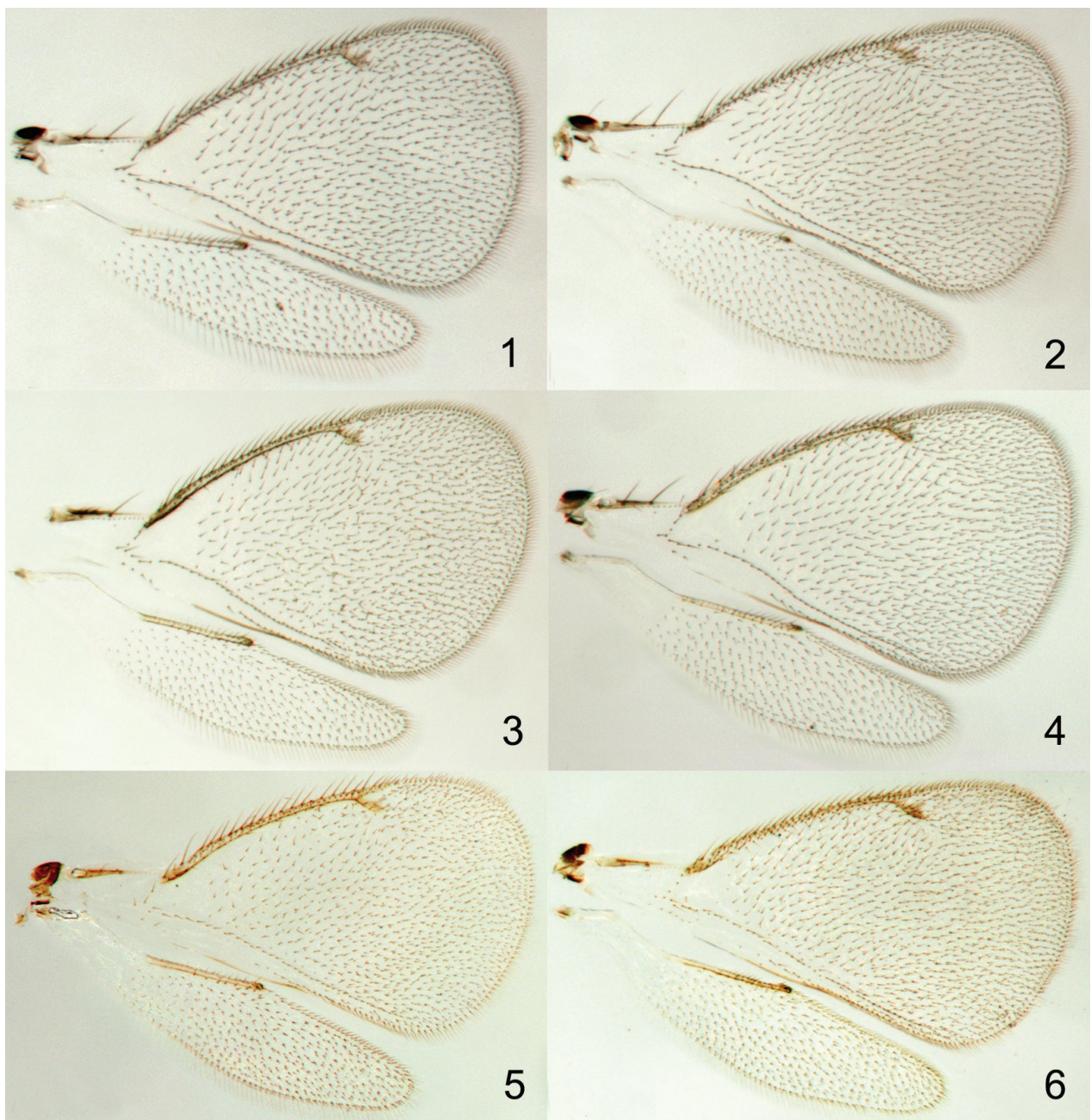

Figures I-6. Achrysocharoides spp., transparent wings: I A. acerianus (Askew), male $\mathbf{2}$ Ditto, female 3 A. platanoidae Hansson \& Shevtsova, male 4 Ditto, female 5 A. butus (Walker), male 6 Ditto, female. Wings on Figs 1-4 from Sweden, Skåne, 2010 5-6 from Wales, 1976.

species groups, two of which were newly created. Hansson and Shevtsova (2010) added two new species to the North American fauna, increasing the total to 20 species. With the two new species described here this total is now 22, equal to the number of species in Europe. Worldwide, including the two new species described here, 56 species of Achrysocharoides are known. The majority (ten) of the remaining species are from Japan (Kamijo 1990a, b), thus establishing the main distribution of Achrysocharoides as the northern hemisphere. 


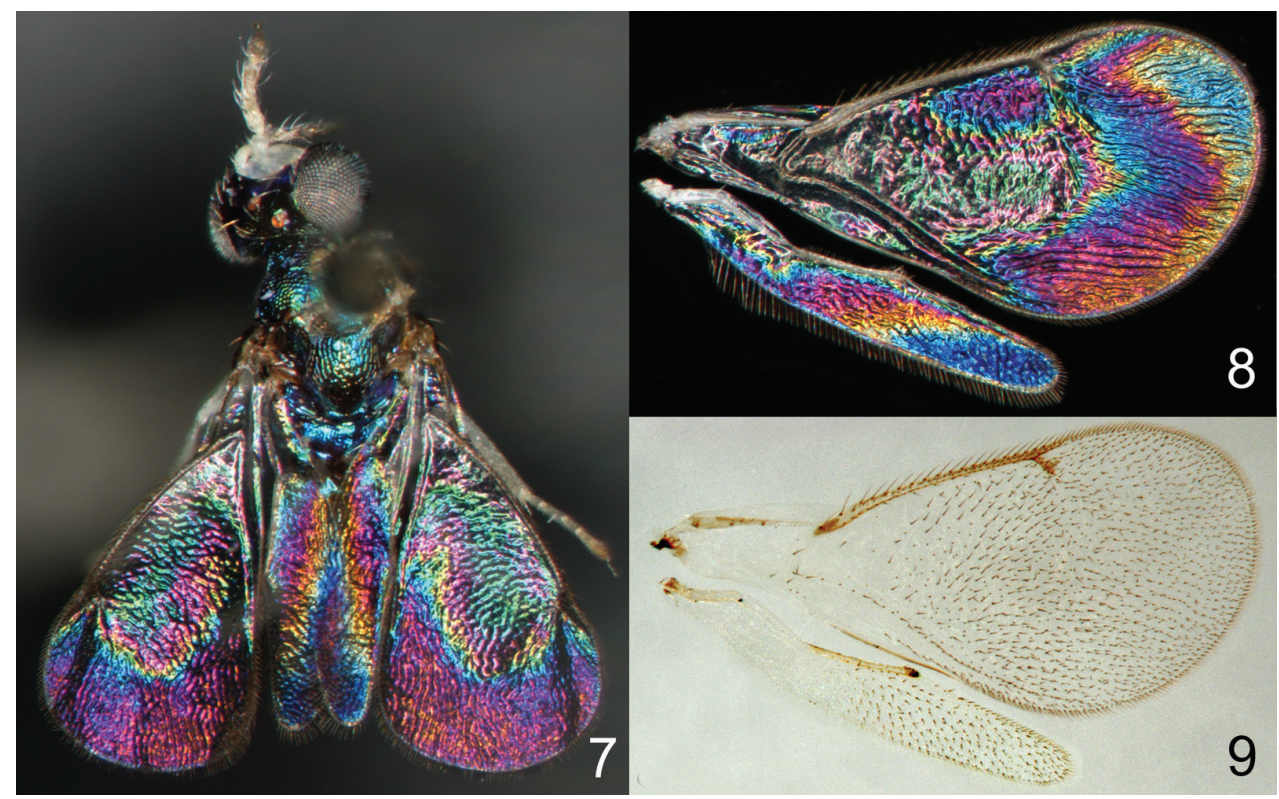

Figures 7-9. Achrysocharoides spp.: 7 A. zwoelferi (Delucchi), male, from Sweden, Blekinge, 1956 8 Undescribed species from USA, Arizona, 1982, male, wing interference pattern (WIP) 9 The same wings as in Fig. 8 in transparent mode.

\section{Material and methods}

The observation and documentation of WIPs do not require a special light source and can be done on any dry specimen with intact wings arranged against a dark background. However, to make the illustrations comparable all photos in this paper as well as in Shevtsova et al. (2011) are of wings removed from the specimens and horizontally arranged, and with the same magnification (6x). To achieve this, the wings are flattened between a glass slide and a glass cover slip on top of the wings. The underside of the glass slide is stained with a drop of black ink to make the background pitch black and homogeneous (this was proposed by J. Kjærandsen). In a few cases where the wings could not be properly flattened the slide was slightly tilted so that the pattern in a non-flattened area, e.g. in a wrinkle, became visible and could be documented. This area was then manually combined in Adobe Photoshop with the initial horizontal photo of the wing, thus showing the complete pattern. A Nikon SMZ1000 stereomicroscope and 5MP Nikon DS-L1 camera were used to take photos of the wings at different focus levels, and Helicon Focus Pro version 4.75 software was used to merge them into a single image. WIPs are usually too shiny for the camera to balance brightness automatically and therefore the brightness was individually adjusted in Adobe Photoshop. Subsequent editing included cleaning and cropping of the photo. After the fore and hind wings were documented they were glued back to the card with the original specimen, which retained the second pair of wings for future observations - structural colours disappear on glued or slide mounted wings (Figs 1-6). The images of transparent wings in this paper are from temporary slide 
preparations with wings mounted in a water-soluble clear gel. The scanning electron microscopy (SEM) images (Figs 11, 13, 15, 17, 66-71, 82-87) are from uncoated specimens on their original card mountings. The photos were taken in low vacuum mode via a backscattered electron detector on a JEOL JSM 5600LV microscope.

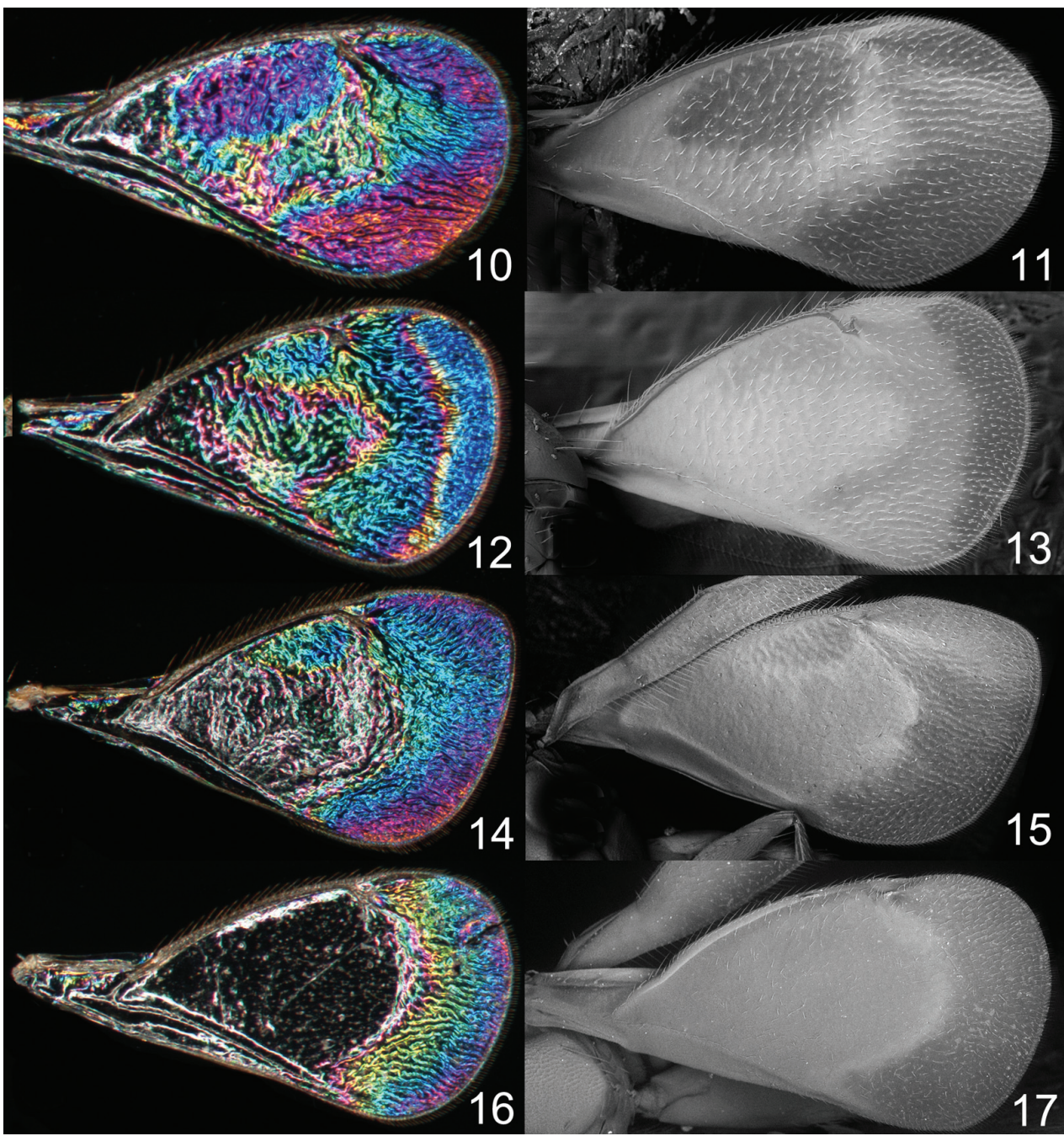

Figures 10-17. Achrysocharoides spp., males, wing interference patterns (WIPs) to the left, scanning electron micrographs from uncoated wings to the right: I0-I I A. robiniae Hansson \& Shevtsova 12-13 A. butus (Walker) I4-I5 A. latreilleii (Curtis) 16-I7 A. albiscapus (Delucchi).

\section{Morphological abbreviations and acronyms}

$\mathrm{HE}=$ height of eye; HW = height of fore wing; LG = length of gaster; $\mathrm{LM}$ = length of marginal vein; LW = length of fore wing, measured from base of marginal vein to apex of wing; $\mathrm{MM}=$ length of mesosoma; $\mathrm{MS}=$ malar space; $\mathrm{OOL}=$ distance between one 
posterior ocellus and eye; $\mathrm{PM}=$ length of postmarginal vein; $\mathrm{POL}=$ distance between posterior ocelli; $\mathrm{POO}=$ distance between posterior ocelli and occipital margin; ST = length of stigmal vein; WH = width of head; WM = width of mouth; WT = width of thorax. For illustrations of the morphological terms see http://www.neotropicaleulophidae.com/.

Collection acronyms, for the deposition of type material: BMNH = Natural History Museum, London, England; CAES = Connecticut Agricultural Experiment Station, New Haven, U.S.A; CNC = Canadian National Collection of Insects, Ottawa, Canada.

\section{Results and discussion}

The paper by Hansson and Shevtsova (2010) included two cryptic Achrysocharoides species from Acer, A. platanoidae Hansson \& Shevtsova from Acer platanoides and A. acerianus (Askew) from $A$. pseudoplatanus, and two cryptic species from Robinia pseudoacacia, A. robiniae and $A$. robinicolus, both described in that paper. The transparent wings in these four species are very similar and identical between males and females (Figs 1-4). Nevertheless the initial differences distinguishing these cryptic species were found in the wing morphology through distinct WIPs, which visualize uneven thickness of the wing membrane through different interference colours (Shevtsova et al. 2011).

In both cryptic cases only one of the species displays a distinct species specific WIP, and in males only, while conspecific females and both sexes of the other cryptic species have similar WIPs. In the two Achrysocharoides species associated with Acer only males of $A$. platanoidae have a distinctive WIP with an eye-catching blue spot in the upperapical corner of the fore wing (Figs 18-21). The female WIP of $A$. platanoidae displays no such spot (Figs 22-23) and is very similar to A. acerianus, which has the same WIP in both sexes (Figs 24-27). In the two other cryptic species, associated with Robinia pseudoacacia, only males of $A$. robiniae display a very characteristic WIP with a large ovate spot below the marginal vein. The male WIP also has an extended and usually green triangular area in the medio-apical part of the fore wing (Figs 28-33). In the female WIP the triangular area is usually less pronounced than in males and the submarginal ovate spot is significantly smaller (Figs 34-35). As the female does not display the characteristic features in these patterns as distinctly as the male, it can be confused with the female of $A$. robinicolus, which has the same WIP in both sexes (Figs 36, 37).

The two North American species described here, A. maieri and A. serotinae, are known only from, and are probably confined to, Phyllonorycter species on Prunus. Males can be distinguished through easy-to-see differences in the external morphology, e.g. the shape of the head (Figs 57, 67, 73, 83) but females are not so distinct and display less divergent characters (Figs $56,66,72,82$ ). Even though the wings of $A$. maieri and $A$. serotinae appear very similar in transparent mode (similar to Figs 1-6) the WIPs in these species are distinct and specific. Apart from being useful in the discrimination of the females, in this case WIPs are also useful for the association of otherwise 
dimorphic males and females of the same species. The external morphology in these species exhibits a pronounced sexual dimorphism and as they share the same host it is not obvious which females and males are conspecific. However, there is one important character they have in common - WIPs, which are identical in both sexes but different between the species. Achrysocharoides maieri has a WIP with wide coloured cross bands on the fore wing (Figs 64-65), and A. serotinae has a quite featureless almost unicoloured WIP (Figs 80-81).

Additional examples of Achrysocharoides species with distinct and sexually dimorphic WIPs are A. butus (Walker) (Figs 38-43) and A. latreilleii (Curtis) (Figs 46-49) where characteristic and specific WIPs, again, are confined to males. Female WIPs of these two species are similar (Figs 44-45, 50-51), and as in females of A. platanoidae and $A$. acerianus (Figs 22-23, 26-27), and A. robiniae and A. robinicolus (Figs 34-35, 37), WIPs are not useful for species recognition. The WIP of male A. butus is similar to that of male $A$. platanoidae because the apical margin of the fore wing has a blue spot in both species. However, in A. butus this spot is prolonged and reaches along a major part of the apical margin (Figs 38-43) whereas in A. platanoidae the spot is short and confined to the upper-apical corner of the fore wing (Figs 18-21). The male of $A$. latreilleii is distinct not only in the truncate shape of the fore wing but also in its WIP (Figs 46-49). The basal 2/3 of the fore wing is the thickest part of the wing membrane and due to its micromorphology reflects very weak interference colours (Shevtsova et al. 2011). The apical part of the fore wing, and a small submarginal spot located in the corner between marginal and stigmal veins, are brightly coloured. The potential of WIPs as a character for separating species can be further demonstrated through two species where only male WIPs are known. Achrysocharoides albiscapus (Delucchi) has a WIP similar to that of A. latreilleii, but differs in having the basal 2/3 of the fore wing completely transparent without colour reflections and no submarginal colour spot (Figs 52-55). The shape of the fore wing is also different between males of these two species. The other species is undescribed, from Arizona, USA (specimen in CNC), and we have only seen a single male. This specimen has a distinctive WIP which emphasizes very unusual shapes of both fore and hind wings. The WIP includes a blue spot in the upper-apical corner of the fore wing (Fig. 8), comparable to A. platanoidae (Figs 18-21) but with the blue spot smaller and differently shaped.

Similar to other morphological characters there is a certain intraspecific variation in WIPs (Figs 18-55), but the species specific traits nevertheless remain clearly recognizable and are reliable for species separation. The intraspecific variation in WIPs can be divided into two types, variation in colour and in shape of patterns. Variation in colour is basically size-dependent - the thickness of the wing membrane usually varies with the size of the specimen and there is a general shift of the hues in WIPs from larger to smaller specimens. Variation in the shapes of pattern outlines of conspecific WIPs is not apparently size dependent but reflects individual differences between specimens the overall pattern nevertheless remains the same.

Wing interference patterns are due to structural organization patterns of the wing membrane where areas of different thickness reflect certain interference colours (Shevt- 

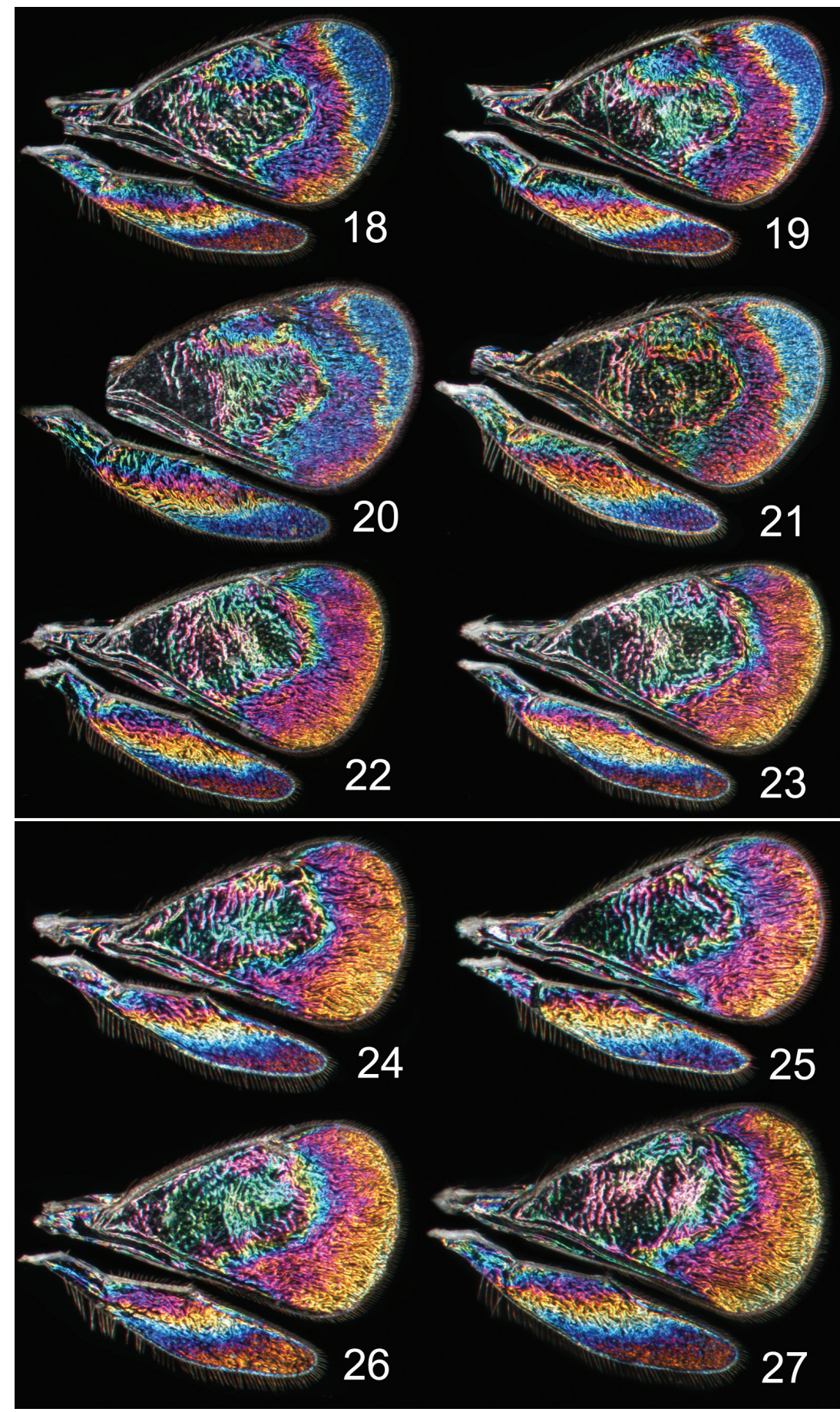

Figures 18-27. Achrysocharoides spp., wing interference patterns (WIPs): 18-23 A. platanoidae Hansson \& Shevtsova I 8-2 I Males 22-23 Females 24-27 A. acerianus (Askew) 24-25 Males 26-27 Females. All wings from specimens from Sweden, Skåne, 2010. 

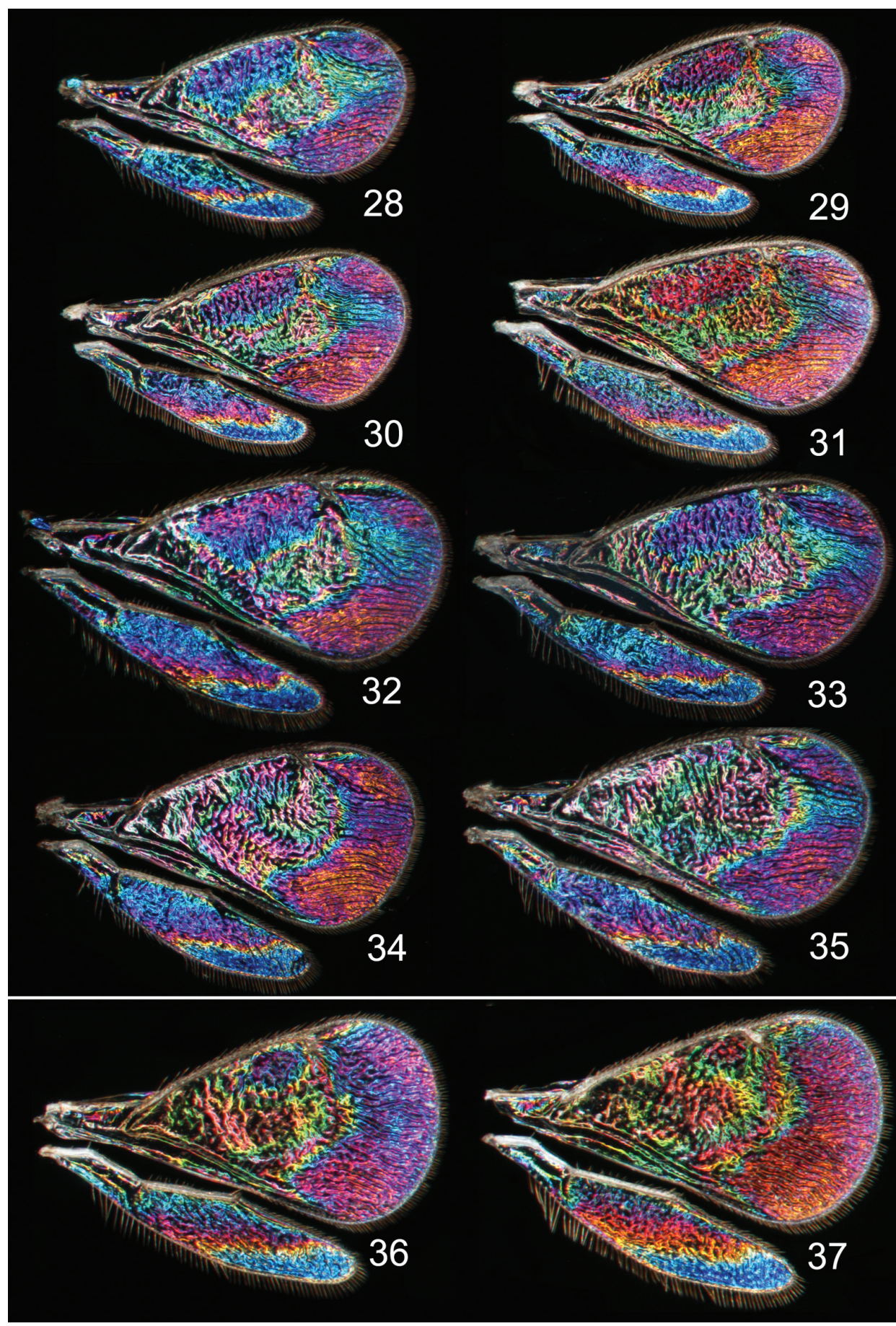

Figures 28-37. Achrysocharoides spp., wing interference patterns (WIPs): 28-35 A. robiniae Hansson \& Shevtsova 28-33 Males 34-35 Females 36-37 A. robinicolus Hansson \& Shevtsova 36 Male 37 Female. Wings on Figs 28-31, 34-37 from USA, Connecticut, 2002 32, 33, from Hungary, Vas Co., 2002. 


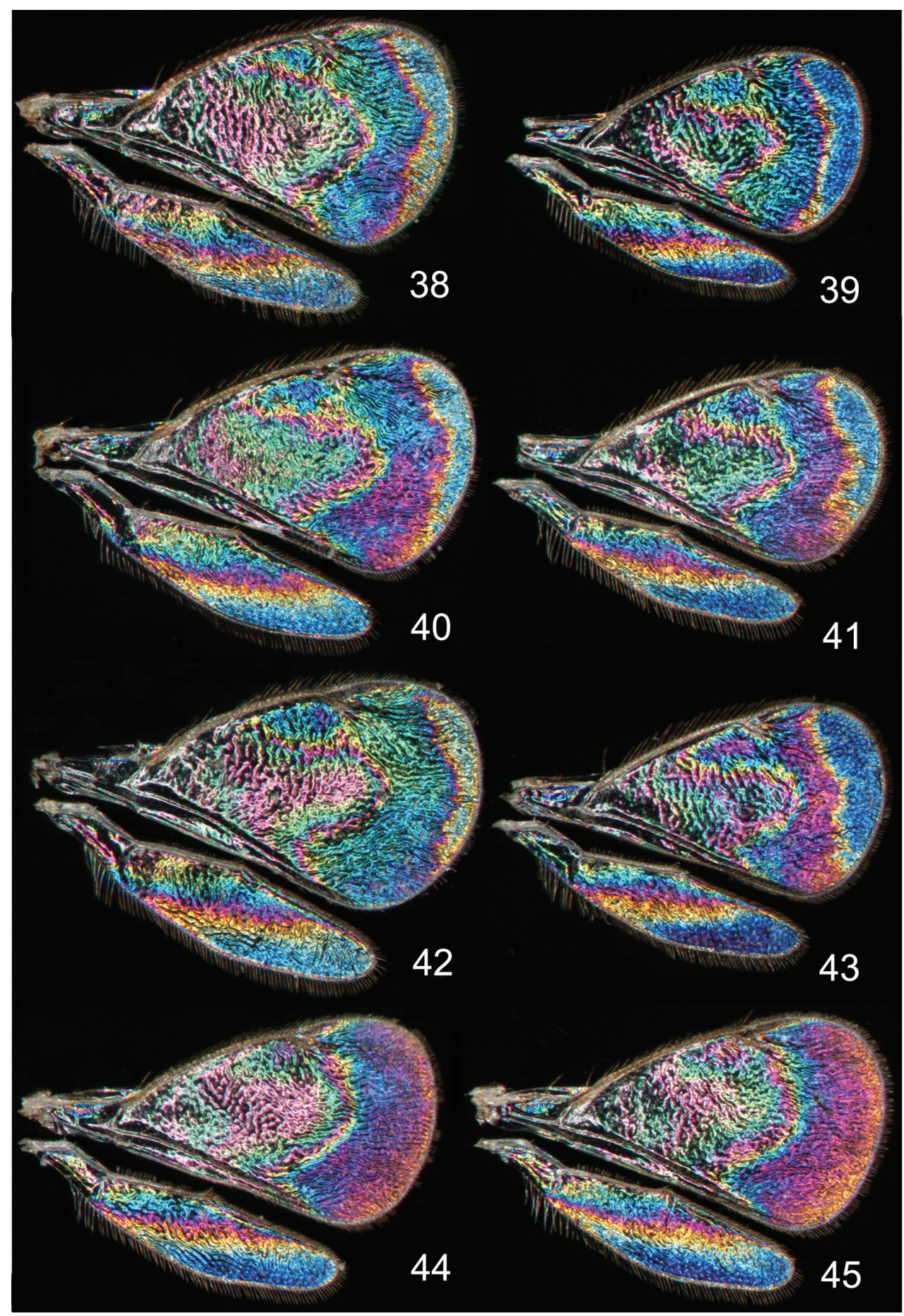

Figures 38-45. Achrysocharoides butus (Walker), wing interference patterns (WIPs): 38-43 Males 44-45 Females. Wings on Figs 38, 40-45 from Wales, 197639 from Sweden, Skåne, 2010. 

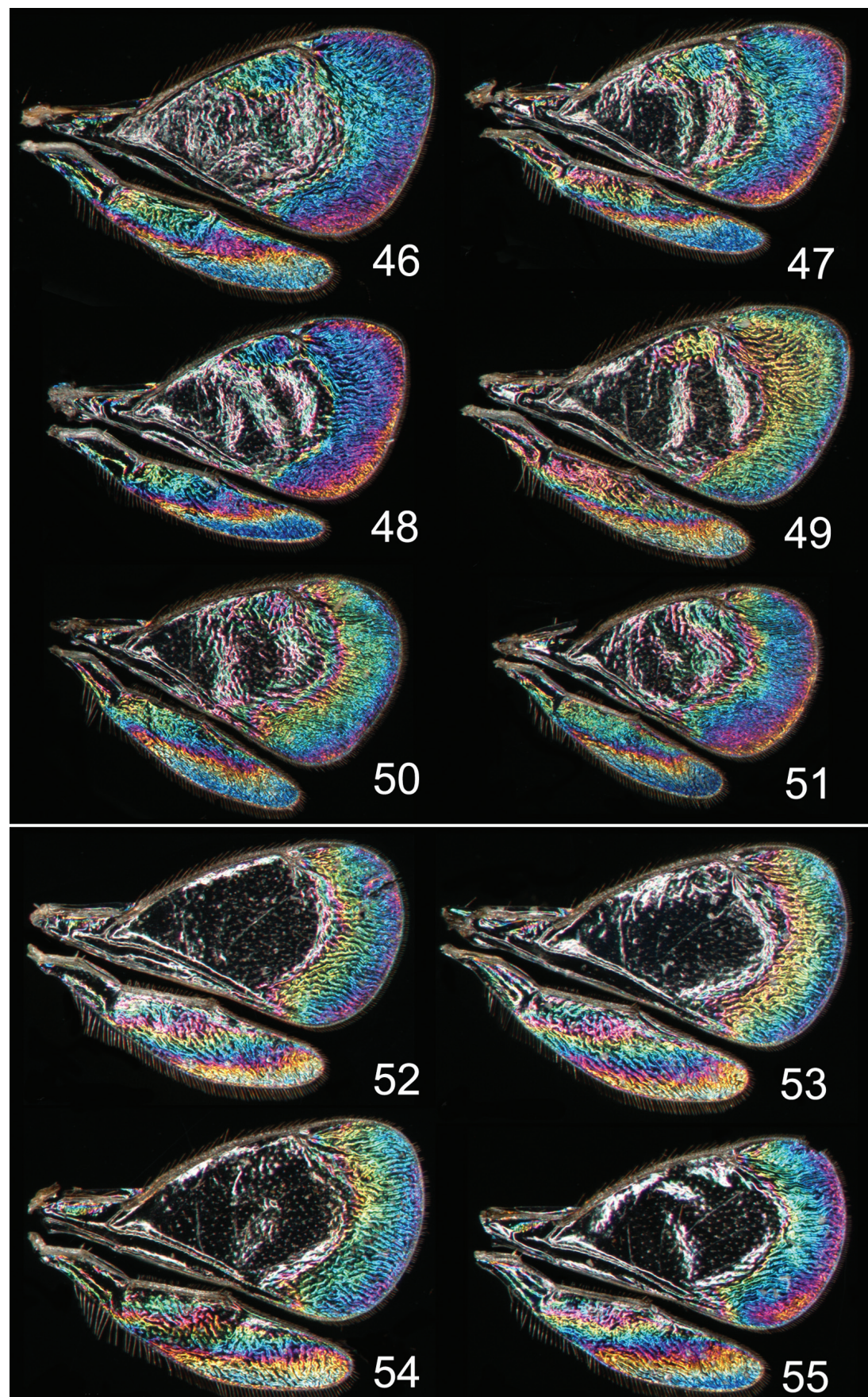

Figures 46-55. Achrysocharoides spp., wing interference patterns (WIPs): 46-5 I A. latreilleii (Curtis) 46-49 Males 50-51 Females 52-55 A. albiscapus (Delucchi), males. Wings on Figs 46, 47, 49-51 from England, Surrey 1986-2004 48 from Sweden, Skåne, 2010; 52, 53, 55 from Greece, Crete, 1997 54 from France, 1984. 
sova et al. 2011). We have found that the uneven thickness of the wing membrane also can be demonstrated and authenticated through the contrast in grey scale SEM images of uncoated wings. The SEM images created through back-scattered electrons (BSEs) visualize specific patterns on wings (Figs 11, 13, 15, 17). These patterns fully correspond to the approximate mapping of the wing thickness based on WIPs where the thickness of the wing membrane at any point can be estimated by the reflected interference colour (Shevtsova et al. 2011). The thickness gradient as seen through grey scale gradients in SEM images is due to specific properties of BSEs which have the escape depth of up to hundreds of nanometers (Egerton 2005). This means that the signal comes from a sample depth in the range comparable to membrane thickness in wings producing bright WIPs, i.e. 100-600 $\mathrm{nm}$. In uncoated wings the primary (incident) electrons are scattered inside the membrane and reflected as BSEs to the back-scatter detector. In thick areas of the membrane the amount of BSEs is large, resulting in a strong signal, while thin areas of the membrane produce fewer BSEs and a weaker signal, thus displaying light and dark grey hues respectively. If the wings are coated with platinum or gold, the resulting picture is completely different due to secondary electrons (SEs) which are generated only within a very small distance below the surface as the escape depth of SEs is less than two nanometers (Egerton 2005), thus displaying the surface of the specimen rather than the underlying structure. In Shevtsova et al. (2011) secondary electron images were used to illustrate the microstructures of the wing surface, such as the ridges of membrane corrugations with rows of setae.

The clarification of the two cryptic species on Acer spp. (Hansson and Shevtsova 2010, Shevtsova et al. 2011) requires a correction of the molecular information deposited in Genbank. At the time of the publication of Lopez-Vaamonde et al. (2005) the identity of the Achrysocharoides species associated with Acer spp. was not clear, and "Achrysocharoides acerianus ex Acer platanoides" and "Achrysocharoides sp. ex Acer pseudoplatanus" in Lopez-Vaamonde et al. (2005) are A. platanoidae and A. acerianus respectively, which is confirmed here with new molecular analyses compared to data of "Achrysocharoides sp." and "A. acerianus" in Genbank. Our new sequences include CO1, 18S, 28S and will be deposited in Genbank.

\section{Species descriptions}

\section{Achrysocharoides maieri sp. $\mathrm{n}$.}

urn:lsid:zoobank.org:act:2E20B2E3-557F-413E-8729-D9ADD646FE3C

http://species-id.net/wiki/Achrysocharoides_maieri

Figures 56-71

Material. HOLOTYPE male (CNC) glued to a card, labeled "U.S.A.: Connecticut, New Haven Co., New Hamden, Lockwood Farm, 1.viii.1980, C.T. Maier”, “Tentiform mine of Phyllonorycter propinquinella on Prunus serotina, emerged in laboratory within 3 weeks". PARATYPES: 1 female 3 males with same label data as holotype 
(BMNH, CAES, CNC)); 1 male labeled "U.S.A.: Connecticut, Tolland Co., Willington, 21.x.1981, Chris T. Maier", "Mines of Phyllonorycter propinquinella on black cherry, Prunus serotina, on 21.x.1981, chilled outdoors, parasitoid emerged in laboratory in April 1982" (CNC); 3 females "U.S.A.: Connecticut, New Haven Co., North Haven, 1.vii.1981, C.T. Maier", "Tentiform mine of Phyllonorycter nr crataegella on Prunus pensylvanica, emerged in laboratory within 3 weeks" (BMNH, CNC); $2 \mathrm{fe}-$ males 1 male from same locality and same host as previous but collected 2.vi.1986 (BMNH).

Diagnosis. Both sexes: fore wing WIP with several distinct wide colourful crossbands traversing the wing (Figs 64, 65), fore coxa white, hind coxa except apex golden green (Figs 62, 63); male: scape widest just below median part, with a single sparse row of setae along ventral margin (Fig. 59), antennal scrobes join frontal suture wide apart (Figs 67), vertex with long forward pointing setae (Fig. 69) - setae about as long as distance between posterior ocelli, upper frons without setae (Fig. 67), frons very large and wide (Fig. 67) - at its widest part $0.8 \mathrm{X}$ as wide as width of head; female: scape predominantly white and widest medially, with a single row of setae along ventral margin, propodeum smooth (Fig. 70), frons above frontal suture with raised and strong reticulation (Fig. 66).

Description. Female. Length 1.1-1.5 mm. Scape white with inner apical tip infuscate; pedicel pale brown; flagellum dark brown (Fig. 58). Frons below frontal suture golden green to golden red, above frontal suture bluish green metallic (Fig. 56). Vertex inside ocellar triangle golden red, outside ocellar triangle golden green. Mesoscutum golden green with golden red areas - especially so in smooth posterior notaular depressions, to completely golden green (Fig. 60). Scutellum golden red with sides and posterior margin bluish green metallic, to completely golden green (Fig. 60). Propodeum golden red to golden green (Fig. 60). Fore coxa white, mid coxa dark brown with apical 1/3 white to completely dark brown, hind coxa golden green (Fig. 62); femora, tibiae and tarsi on all legs white. Wings without pigmented areas; WIP in fore wing with several distinct wide colourful cross-bands traversing the wing (Fig. 64). Gaster with first two tergites golden green, remaining tergites golden purple with green metallic tinges.

Antenna as in Fig. 58. Frons below level of toruli smooth and shiny (Fig. 66), between level of toruli and frontal suture with raised and strong reticulation lateral to antennal scrobes, between antennal scrobes with very weak reticulation, above frontal suture with raised and strong reticulation. Vertex inside ocellar triangle with engraved and weak reticulation, outside ocellar triangle smooth and shiny (Fig. 68). Occipital margin rounded.

Pronotal collar without transverse carina (Fig. 70). Mesoscutum with raised and strong reticulation (Fig. 70), meshes of reticulation smaller on sidelobes than on midlobe, midlobe with pits (i.e. with very strong reticulation) posteromedially; notauli as smooth impressions in posterior $2 / 3$. Scutellum with very weak reticulation and shiny, smooth along posterior margin, with 3-4 pits medially on either side of imaginary median longitudinal line (Fig. 70). Dorsellum flat and smooth, anterolaterally with two foveae. Propodeum smooth and shiny (Fig. 70); propodeal callus with three setae. Fore wing speculum closed below. Petiole conical without shoulders. 


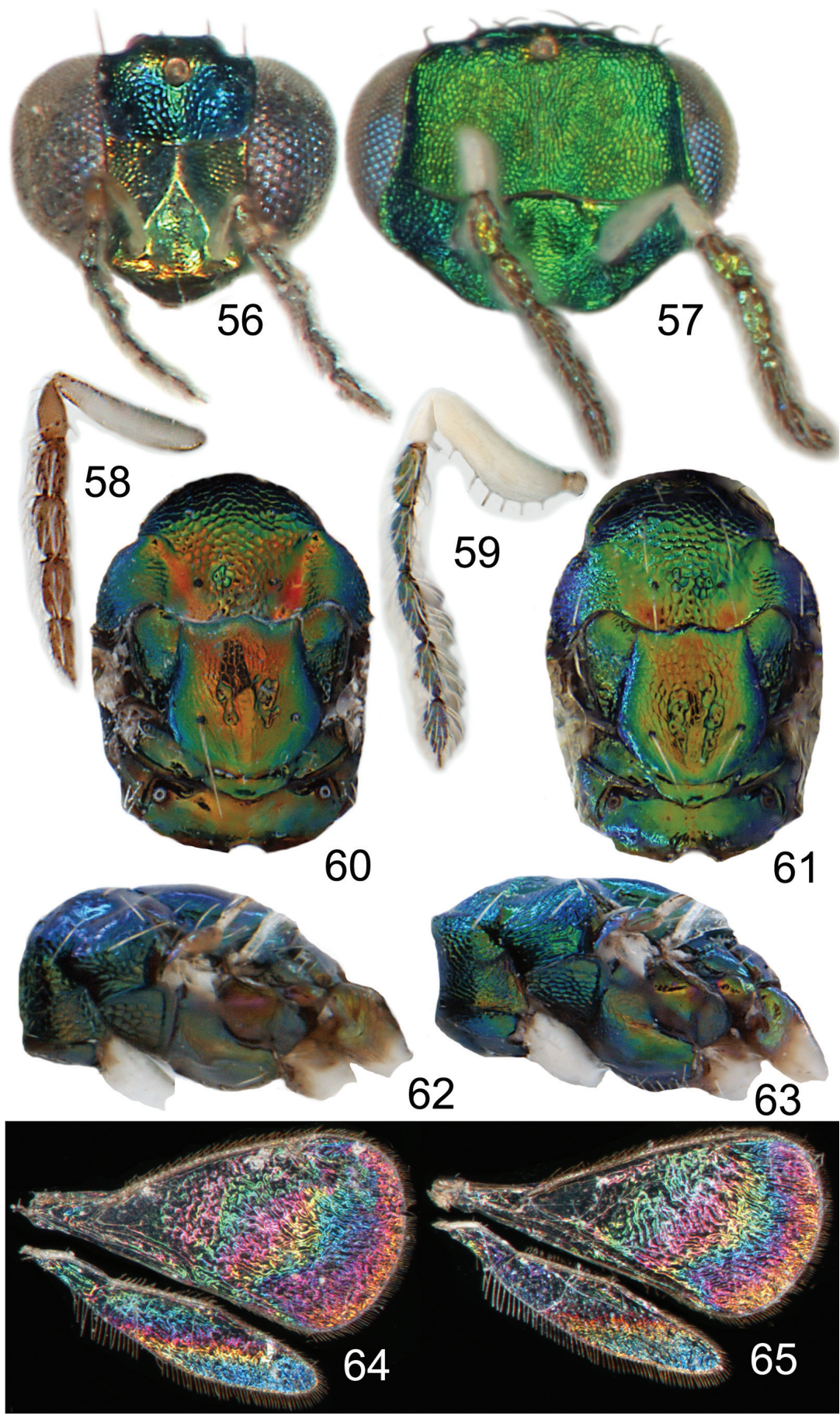

Figures 56-65. Achrysocharoides maieri sp. nov.: $\mathbf{5 6}$ Head frontal, female $\mathbf{5 7}$ Ditto, male $\mathbf{5 8}$ Antenna lateral, female 59 Ditto, male 60 Mesosoma dorsal, female 6 I Ditto, male 62 Mesosoma lateral, female 63 Ditto, male 64 Wing interference pattern (WIP), female 65 Ditto, male. 

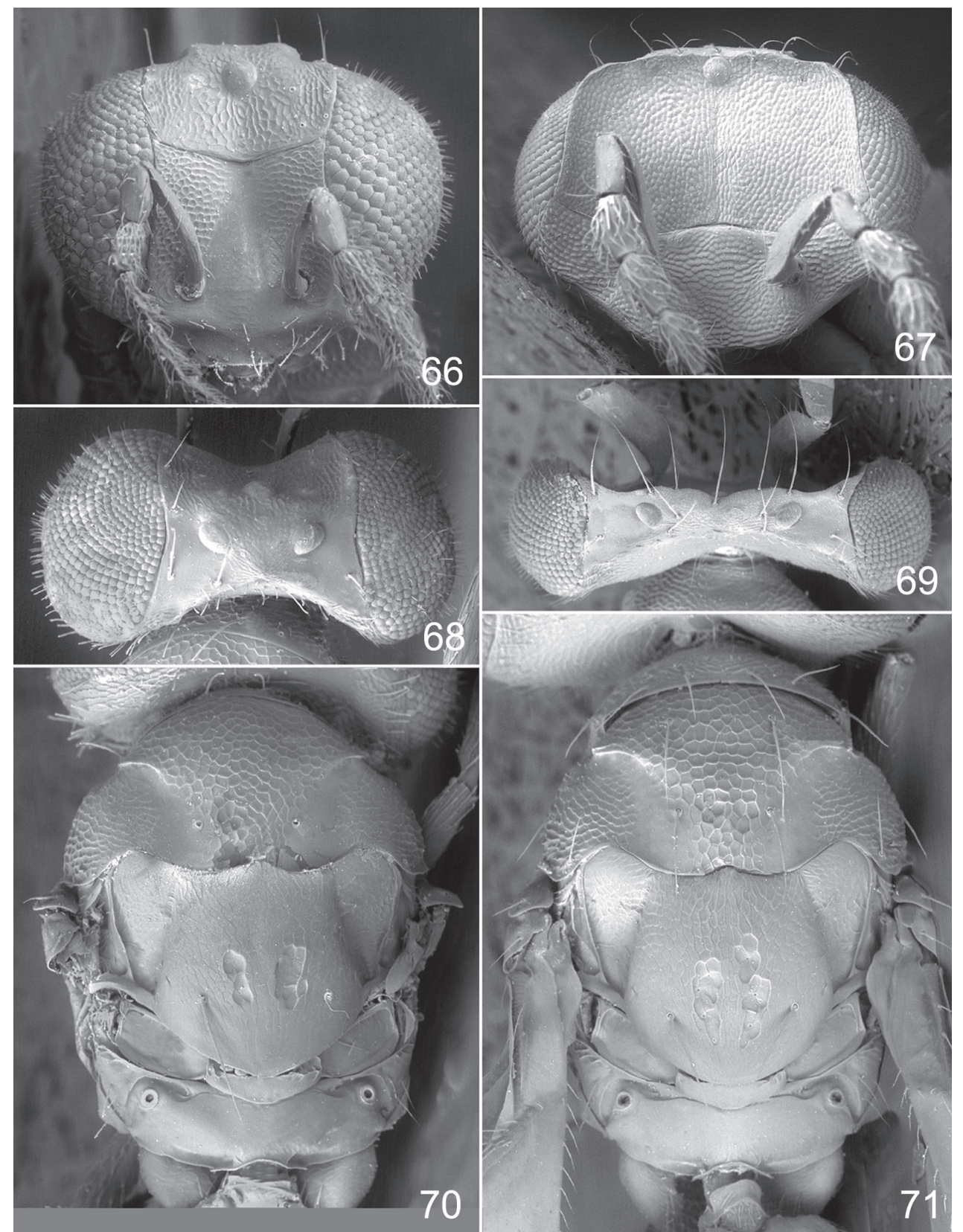

Figures 66-7 I. Achrysocharoides maieri sp. n.: 66 Head frontal, female 67 Ditto, male 68 Vertex, female 69 Ditto, male 70 Mesosoma dorsal, female. 7 I Ditto, male.

Ratios. HE/MS/WM = 5.0/1.0/2.3; POL/OOL/POO = 2.6/1.1/1.0; WH/WT = 1.2; $\mathrm{LW} / \mathrm{LM} / \mathrm{HW}=1.6 / 1.0 / 1.0 ; \mathrm{PM} / \mathrm{ST}=1.0 ; \mathrm{MM} / \mathrm{LG}=0.8-0.9$.

Male. Length 1.4-1.5 mm. Scape and pedicel white; flagellum dark brown with golden green tinges (Fig. 59). Frons green metallic (Fig. 57). Vertex inside ocellar tri- 
angle golden red, outside ocellar triangle golden green. Mesoscutum golden green with posterior $1 / 3$ of notaular depressions golden red (Fig. 61). Scutellum golden red with sides bluish green metallic (Fig. 61). Propodeum golden green (Fig. 61). Fore coxa white, mid coxa dark brown with apical $1 / 3$ white to completely dark brown, hind coxa golden green with apical half white (Fig. 63); femora, tibiae and tarsi on all legs white. Wings without pigmented areas; WIP very similar to that of the female (Fig. 65). Gaster with tergites 1-2 golden green with a large white spot medially, remaining tergites dark brown with purple metallic tinges.

Antenna as in Fig. 59, i.e. scape widest just below middle. Frons with engraved and strong reticulation (Fig. 67); antennal scrobes reaching frontal suture wide apart; transverse ridge straight medially. Vertex inside ocellar triangle with engraved and very weak reticulation, outside ocellar triangle smooth and shiny (Fig. 69); anterior part with a row of seven long and proclinate setae. Occipital margin rounded.

Pronotal collar without transverse carina (Fig. 71). Mesoscutum with raised and strong reticulation (Fig. 71), meshes of reticulation smaller on sidelobes than on midlobe, midlobe with pits (i.e. with very strong reticulation) posteromedially; notauli as smooth impressions in posterior $2 / 3$. Scutellum very weak reticulation and shiny, smooth along posterior margin, with 3-4 pits medially on either side of imaginary median longitudinal line (Fig. 71). Dorsellum flat and smooth, anterolaterally with two foveae. Propodeum smooth and shiny (Fig. 71); propodeal callus with three setae. Fore wing speculum closed below. Petiole conical without shoulders.

Ratios. HE/MS/WM = 2.3/1.0/1.3; POL/OOL/POO = 14.4/6.4/1.0; WH/WT $=1.4 ; \mathrm{LW} / \mathrm{LM} / \mathrm{HW}=1.5 / 1.0 / 1.0 ; \mathrm{PM} / \mathrm{ST}=1.0 ; \mathrm{MM} / \mathrm{LG}=1.0$.

Etymology. Named after Dr. Chris T. Maier, Entomologist at the Connecticut Agricultural Experiment Station, who collected all material of the two new species described here.

Distribution. U.S.A. (Connecticut).

Hosts. Phyllonorycter propinquinella (Braun) (Lepidoptera: Gracillariidae) on black cherry (Prunus serotina), and Phyllonorycter nr crataegella on pin cherry (Prunus pensylvanica).

\section{Achrysocharoides serotinae sp.n.}

urn:lsid:zoobank.org:act:C0EA95FF-793E-46BF-AF38-E300F345AB48

http://species-id.net/wiki/Achrysocharoides_serotinae

Figures $72-87$

Material. HOLOTYPE male (CNC) glued to a card, labelled "U.S.A.: Connecticut, New Haven Co., North Haven, 30.ix.1981, Chris T. Maier", "Adult parasitoid labreared from tentiform mine of Phyllonorycter propinquinella collected on black cherry, Prunus serotina on 30.ix.1981". PARATYPES: 1 male with same label data as holotype (CNC); 2 females labeled "U.S.A.: Connecticut, Tolland Co., Union, 23.vi.1981, Chris T. Maier", "Adult parasitoid lab-reared from tentiform mine of Phyllonorycter propinquinella collected on black cherry, Prunus serotina on 23.vi.1981" (CNC). 

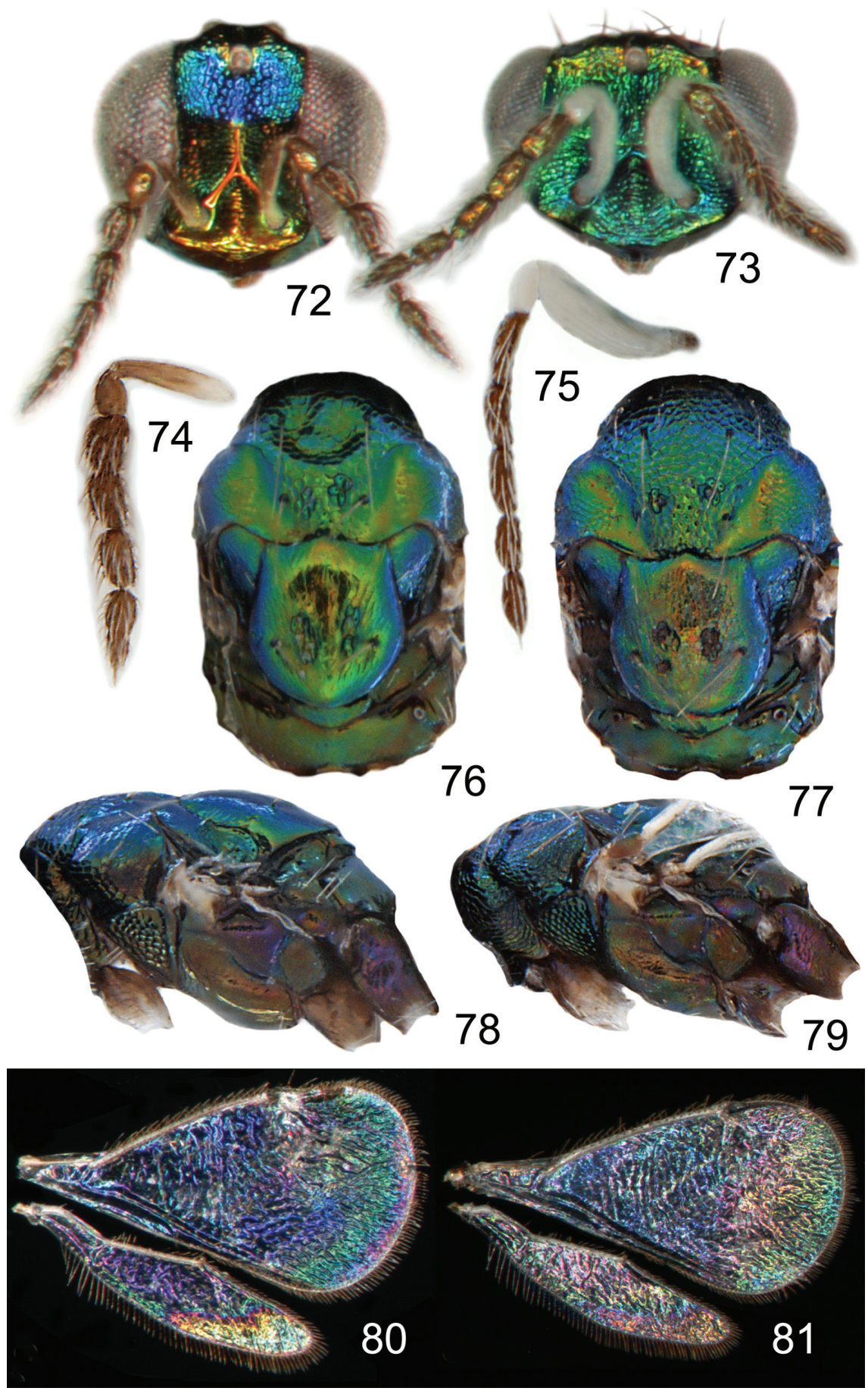

Figures 72-81. Achrysocharoides serotinae sp. n.: $\mathbf{7 2}$ Head frontal, female $\mathbf{7 3}$ Ditto, male 74 Antenna lateral, female 75 Ditto, male 76 Mesosoma dorsal, female 77 Ditto, male 78 Mesosoma lateral, female 79 Ditto, male 80 Wing interference pattern (WIP), female 8 I Ditto, male. 
Diagnosis. Both sexes: fore wing WIP almost unicoloured, gradually changing hue from purple to green towards the margin, without any distinct details such as lines or spots (Figs 80,81), fore coxa predominantly dark brown, hind coxa golden green (Figs 78,79 ); male: scape with about same width throughout, with a single sparse row of setae along ventral margin, antennal scrobes joining on frontal suture (Fig. 73, 83), vertex with long forward pointing setae (Fig. 85) - setae at most as long as distance between posterior ocelli, upper frons without setae (Fig. 83); female: scape pale brown and widest medially, with a single row of setae along ventral margin (Fig. 74), propodeum smooth (Fig. 86), frons above frontal suture with raised and strong reticulation (Fig. 82).

Description. Female. Length $1.2-1.3 \mathrm{~mm}$. Scape and pedicel pale brown; flagellum dark brown (Fig. 74). Frons below frontal suture golden red, above frontal suture bluish green metallic (Fig. 72). Vertex inside ocellar triangle golden red, outside ocellar triangle golden green. Mesoscutum green metallic with blue metallic tinges, smooth parts of notaular depression golden green (Fig. 74). Scutellum golden green with sides and posterior margin bluish green metallic (Fig. 74). Propodeum golden green with blue metallic tinges (Fig. 74). Fore coxa dark brown with apical 1/3 white, mid coxa dark brown, hind coxa purple metallic (Fig. 78); femora, tibiae and tarsi on all legs white. Wings without pigmented areas; WIP in fore wing almost unicoloured, gradually changing hue from blue to green towards the margin when the membrane becomes gradually thinner (Fig. 80). Gaster with first two tergites golden green, remaining tergites golden purple with green metallic tinges.

Antenna as in Fig. 74. Frons below level of toruli smooth and shiny (Fig. 82), between level of toruli and frontal suture with raised and strong reticulation with antennal scrobes smooth, above frontal suture with raised and strong reticulation. Vertex inside ocellar triangle with engraved and weak reticulation, outside ocellar triangle smooth and shiny (Fig. 84). Occipital margin rounded.

Pronotal collar without transverse carina (Fig. 86). Mesoscutum with raised and strong reticulation (Fig. 86), meshes of reticulation smaller on sidelobes than on midlobe, midlobe with singular pits (i.e. with very strong reticulation) posteromedially; notauli as smooth impressions in posterior $2 / 3$. Scutellum with very weak reticulation and shiny, smooth along posterior margin, with 2-4 pits medially on either side of imaginary median longitudinal line (Fig. 86). Dorsellum flat and smooth, anterolaterally with two foveae. Propodeum smooth and shiny (Fig. 86); propodeal callus with three setae. Fore wing speculum closed below. Petiole conical without shoulders.

Ratios. HE/MS/WM = 3.7/1.0/1.6; $\mathrm{POL} / \mathrm{OOL} / \mathrm{POO}=1.7 / 1.0 / 1.0 ; \mathrm{WH} / \mathrm{WT}=$ $1.2 ; \mathrm{LW} / \mathrm{LM} / \mathrm{HW}=1.6 / 1.0 / 1.0 ; \mathrm{PM} / \mathrm{ST}=1.0 ; \mathrm{MM} / \mathrm{LG}=0.8-0.9$.

Male. Length $1.4 \mathrm{~mm}$. Scape and pedicel white; flagellum dark brown (Fig. 75). Frons green metallic (Fig. 73B). Vertex inside ocellar triangle golden red, outside ocellar triangle golden green. Mesoscutum golden green with anterior part blue (Fig. 77). Scutellum golden green with golden red tinges and with lateral parts blue (Fig. 77). 

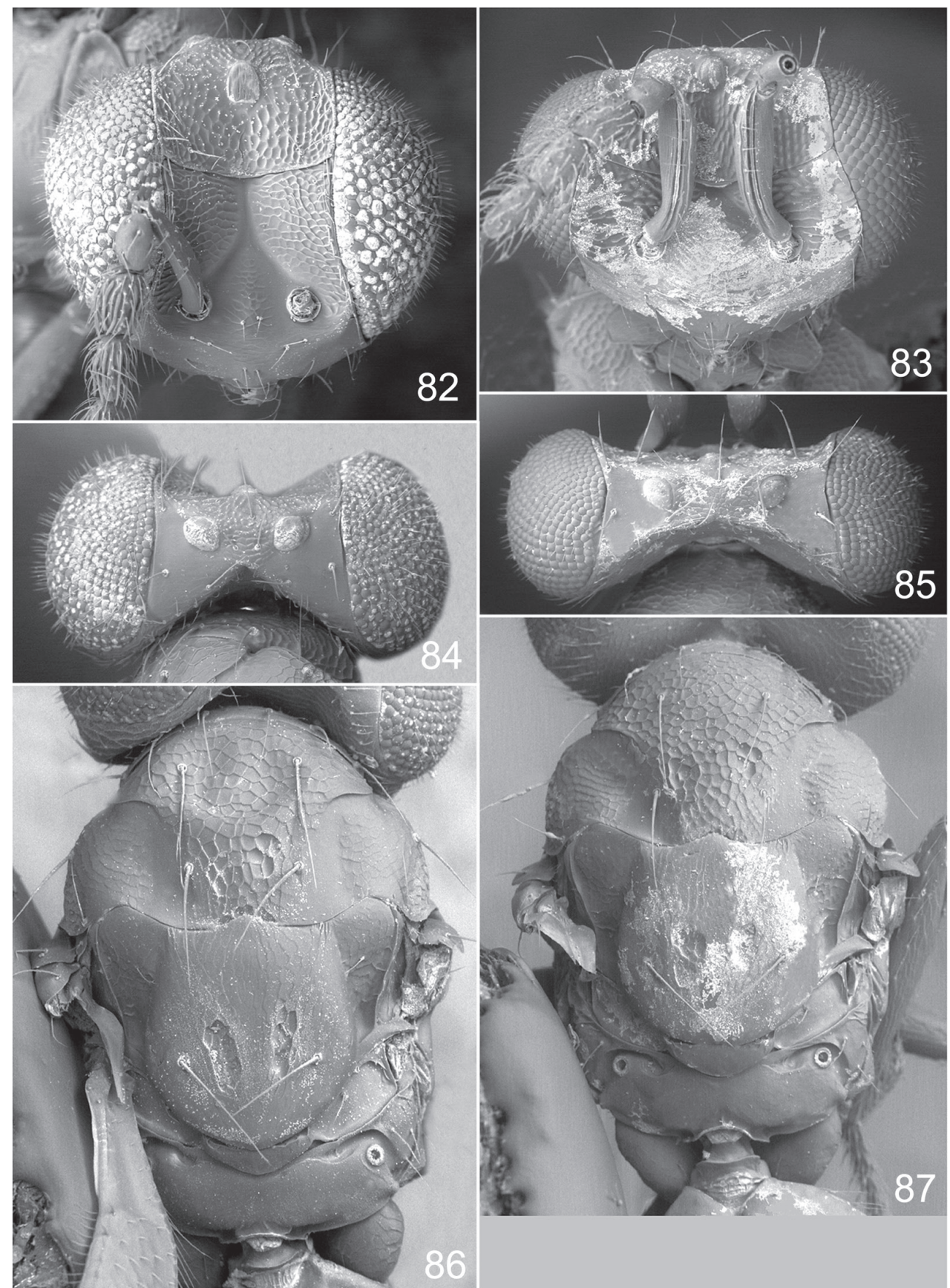

Figures 82-87. Achrysocharoides serotinae sp. n.: $\mathbf{8 2}$ Head frontal, female $\mathbf{8 3}$ Ditto, male $\mathbf{8 4}$ Vertex, female 85 Ditto, male 86 Mesosoma dorsal, female 87 Ditto, male. 
Propodeum golden green with golden red tinges (Fig. 77). Fore coxa dark brown with apical 1/3 white, mid coxa dark brown, hind coxa purple metallic (Fig. 79); femora, tibiae and tarsi on all legs white. Wings without pigmented areas; WIP very similar to that of the female (Fig. 81). Gaster with tergites 1-2 dark brown with golden green tinges, remaining tergites dark brown with weak metallic tinges, over tergites 1-3 with a large median white spot.

Antenna as in Fig. 75, i.e. scape with about same width throughout. Frons with raised and strong reticulation, some parts with transverse striation (Fig. 83); antennal scrobes joining on frontal suture; transverse ridge evenly curved. Vertex inside ocellar triangle with engraved and very weak reticulation (Fig. 85), outside ocellar triangle smooth and shiny; anterior part with a row of 3-5 long and forward directed setae. Occipital margin rounded.

Pronotal collar without transverse carina (Fig. 87). Mesoscutum with raised and strong reticulation (Fig. 87), meshes of reticulation smaller on sidelobes than on midlobe, midlobe with pits (i.e. with very strong reticulation) posteromedially; notauli as smooth impressions in posterior $2 / 3$. Scutellum with weak reticulation, smooth along posterior and lateral margins, with 2-5 pits medially on either side of imaginary median longitudinal line (Fig. 87). Dorsellum flat and smooth, anterolaterally with two foveae. Propodeum smooth and shiny (Fig. 87); propodeal callus with three setae. Fore wing speculum closed below. Petiole conical without shoulders.

Ratios. HE/MS/WM = 2.5/1.0/1.3; POL/OOL/POO = 4.6/1.8/1.0; WH/WT = $1.1 ; \mathrm{LW} / \mathrm{LM} / \mathrm{HW}=1.6 / 1.0 / 1.0 ; \mathrm{PM} / \mathrm{ST}=1.0 ; \mathrm{MM} / \mathrm{LG}=0.9$.

Etymology. Named after black cherry (Prunus serotina), the host plant.

Distribution. U.S.A. (Connecticut).

Host. Phyllonorycter propinquinella (Braun) (Lepidoptera: Gracillariidae) on black cherry (Prunus serotina).

\section{Identification of the new species}

In the most recent key to North American Achrysocharoides by Kamijo (1991) the two newly described species both key out to the clypeatus group. To include them in the key to species of this group the following changes can be made:

Females of both species run to couplet 3 , alternative 2 (where $A$. arienascapus falls out). The second alternative is changed to lead to $3 \mathrm{a}$ instead of $A$. arienascapus and then:

3a Fore coxa and scape predominantly brown (Figs 74, 78) ...A. serotinae sp. $\mathbf{n}$.

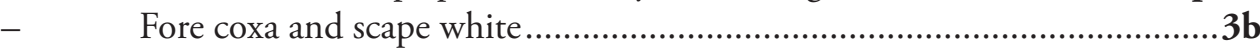

3b Entire frons above frontal suture with raised and strong reticulation (Fig. 66); scutellum with very weak and superficial reticulation (Fig. 70) ... A. maieri sp. $\mathbf{n}$.

- $\quad$ Frons strongly reticulate medially and weakly reticulate laterally; scutellum with strong reticulation

A. arienascapus (Miller) 
Males run to couplet 4:

$4 \quad$ Frons above frontal suture with many short and scattered setae (see fig. 5 in Kamijo (1991)); scape with long dense setae ventrally (see fig. 5 in Kamijo (1991)) A. hirtiscapus (Miller)

- $\quad$ Frons above frontal suture bare (Figs 67, 83); scape with a few short setae along ventral edge (Figs 59, 75) ............................................................5

$5 \mathrm{a} \quad$ Vertex with long setae about as long as distance between posterior ocelli (Figs 69, 85) $.5 b$

- $\quad$ Vertex with long setae at least as long as width of vertex (see fig. 7 in Kamijo (1991)) .5

5b Scape widest close to base (Fig. 59); fore coxa white (Fig. 63)

A. maierisp. n.

- $\quad$ Scape with about same width throughout (Fig. 75); fore coxa predominantly brown (Fig. 79). A. serotinae sp. n.

\section{Acknowledgements}

Our foremost thanks are due to ArtDatabanken who through the Swedish Taxonomy Initiative funds the $\mathrm{PhD}$ project of Ekaterina Shevtsova. Thanks also to Chris T. Maier (at CAES) who generously sent us his material of Achrysocharoides, and to Gary A.P. Gibson and John T. Huber (both at CNC) for the loan of material. The help of Andrew Polaszek (BMNH) with obtaining molecular data for Achrysocharoides acerianus and $A$. platanoidae is highly appreciated. We thank the microscopy unit at the Biology Department, Lund University, for the use of their SEM. We also thank two anonymous reviewers for their useful suggestions.

\section{References}

Askew RR, Ruse JM (1974) Biology and taxonomy of the genus Enaysma Delucchi (Hym., Eulophidae, Entedontinae) with special reference to the British fauna. Transactions of the Royal Entomological Society of London 125(3): 257-294. doi: 10.1111/j.13652311.1973.tb00544.x

Egerton RF (2005) Physical principles of electron microscopy: an introduction to TEM, SEM and AEM. Springer-Verlag gmbh \& Co., 202 pp.

Hansson C (2011) Cornugon (Hymenoptera: Eulophidae: Entedoninae) a new genus from tropical America including ten new species. Zootaxa 2873: 1-26.

Hansson C, Shevtsova E (2010) Three new species of Achrysocharoides Girault (Hymenoptera: Eulophidae) parasitoids of Phyllonorycter spp. (Lepidoptera: Gracillariidae) on Acer platanoides and Robinia pseudoacacia. Zootaxa 2388: 23-43. 
Kamijo K (1990a) Five new species of Achrysocharoides (Hymenoptera, Eulophidae) associated with Leguminosae in Japan. Japanese Journal of Entomology 58(2): 293-302.

Kamijo K (1990b) Descriptions of five new species of Achrysocharoides (Hymenoptera: Eulophidae) from Japan, with notes on species-groups. Akitu (new series) 119: 1-16.

Kamijo K (1991) Revision of North American Achrysocharoides (Hymenoptera: Eulophidae). Akitu (new series) 124: 1-34.

Lopez-Vaamonde C, Godfray HCJ, West SA, Hansson C, Cook JM (2005) The evolution of host use and unusual reproductive strategies in Achrysocharoides parasitoid wasps. Journal of Evolutionary Biology 18: 1029-1041. doi: 10.1111/j.1420-9101.2005.00900.x

Miller CDF (1962) Some Nearctic species of the chalcid genus Enaysma Delucchi (Eulophidae: Entedontinae). The Canadian Entomologist 94: 1039-1052. doi: 10.4039/Ent941039-10

Shevtsova E, Hansson C, Janzen DH, Kjærandsen J (2011) Stable structural color patterns displayed on transparent insect wings. Proceedings of the National Academy of Sciences, USA 108(2): 668-673. doi: 10.1073/pnas.1017393108

Yoshimoto CM (1977) The North American species of the genus Achrysocharoides (Hymenoptera: Eulophidae). The Canadian Entomologist 109: 907-930. doi: 10.4039/Ent109907-7 